\title{
A Study on Community Participation Mode into Luoshijiang Wetland Ecological Tourism in Dali
}

\author{
Mingqiang $\mathrm{Lu}^{1} \&$ Ning Wang ${ }^{1}$ \\ ${ }^{1}$ Qinhuangdao Branch of Northeast Petroleum University, Qinhuangdao 066004, China \\ Correspondence: Mingqiang Lu, Qinhuangdao Branch of Northeast Petroleum University, Qinhuangdao 066004, \\ China. E-mail: 324wxm@sian.com
}

\author{
Received: January 26, 2014 Accepted: February 5, 2014 Online Published: March 17, 2015 \\ doi:10.5539/ach.v7n2p15 URL: http://dx.doi.org/10.5539/ach.v7n2p15
}

\begin{abstract}
Community participation is of great importance to the development of wetland ecological tourism. It is also a significant indicator that evaluates the sound development of ecological tourism. The research conducts an investigation into and analysis on the community participation into Luoshijiang wetland ecological tourism, based on which the paper provides the community participation mode into Luoshijiang wetland ecological tourism as well as the specific guarantee system. The research is of great importance to the coordinated development of environmental, economic and social benefits in Luoshijiang wetland ecological tourism project.
\end{abstract}

Keywords: community participation, Luoshijiang wetland, ecological tourism, development mode

Community participation is of great importance to the development of wetland ecological tourism. It is also a significant indicator that evaluates the sound development of ecological tourism. Dali Erhai River is located in the northwestern urban area of Dali, Yunnan. It is the second largest fresh water lake in Yunnan Province as well as a landmark plateau river on the southwestern edge of China. With the rapid agricultural development in Yunnan, Erhai is under increasingly heavy environmental pressure. It is now at the critical period shifting from mesotrophy to eutrophy. The water in Erhai mainly comes from the northern part. In particular, nitrogen and phosphorus pollutants brought by Luoshijiang River in the northern area are one major reason for the eutrophy of Erhai. In order to control the ecological safety of Erhai, Erhai Management Bureau executed wetland recovery project at the inlet of Luoshijiang River and founded Luoshijiang Wetland Development \& Construction Co., Ltd. to develop wetland ecological tourism in 2009.

At present, Luoshijiang Wetland Community's economic income mainly comes from traditional planting industry, breeding \& raising industry and labor work outside. Household income is in a limited amount. Due to the difference in the geographical locations of communities, traffic, progress of new rural construction and so on, the community cultivation, cultural construction and economic development are imbalanced. At current, there are mainly the following problems in the community participation into wetland ecological tourism: few people join in community participation. The categories are single. Community residents have high passion in community participation, but their ability of participation is weak. They cannot satisfy the demands of development of wetland ecological tourism. The residents' economic foundation is weak in the community. The capital to start community participation is in lack. Wetland ecological tourism and ecological agriculture just start up, so there are few channels for community participation. There are only a few approaches to get benefits. Community participation management is backward. There are no professional community management organizations and personnel in the community. Luoshijiang Wetland Development Construction Co., Ltd. has not formulated relevant plans and regulations to encourage and guide community participation yet. The government does not have specific plans or regulations ensuring community participation. Randomness is very obvious.

In order to ensure the coordinated development of environmental, economic and social benefits in the development of Baoshijiang wetland ecological tourism, the research investigates into the community involved in Luoshijiang wetland ecological tourism and analyzes the current situation of community participation. Moreover, based on this, the research constructs the community participation mode of Luoshijiang wetland ecological tourism and specific guarantee system. The research is of great importance to control the ecological security of Erhai, Dali, promote economic development and social stability in the community, enrich ecological tourism products and enhance the attractiveness of tourism. 


\section{Progress of Research on Ecological Tourism With Community Participation}

\subsection{Theoretical Research Progress}

In the 1970s, western scholars began to pay attention to the effects of tourism on community. In China, relevant researches also start up. Peter (1985) stated the mutual effects between tourism industry and tourism zone. He proposed that the realization of coordinated development of community and tourism should be started from the four perspectives, i.e., accessibility environment, social culture, commercial economy and sound management. Wesche and Drum (1999) thought that community participation mode was closely related to degree of community participation. There were three modes: Community completely possessed and managed the tourism industry. Community and external commercial operators jointly develop community participation mode. Community takes the initiatives to take part in tourism development projects based on its own wills. Chinese scholars propose the assumption of developing ecological tourism by means of shareholding companies considering the actual situation of development of tourism community. In the practical operation, "small-amount credit loans", "company" + "farmer household", "government" + "company" + "rural tourism association" + "tourism agency" and other participation modes are formed (Weng, 2004). Wu (2005) proposed that the core of effectively allocating tourism benefits was that the local residents could obtain effective guarantee. Bao (2006) claimed that the allocation of tourism benefits could not expel the community masses who did not take part in the development of tourism industry directly. Instead, secondary allocation, collective fund transfer \& compensation and other methods should be adopted to ensure that this part of masses could enjoy the dividend of tourism benefits (Bao \& Sun, 2006).

\subsection{Progress of Practical Researches: Analysis of Reference on Domestic and Foreign Wetland Community Participation Mode}

\subsubsection{Guizhou Caohai's "External Project Facilitating Community Participation" Mode}

In 1995, Management Department of Guizhou Caohai Preservation Zone and International Crane Foundation implemented the international cooperation project that combined natural protection and community development in Caohai Wetland in Guizhou. The project applied the mode of external project's facilitating community participation. In Bojiwan Village, it executed TUP for the purpose of poverty relief and CTF four the purpose of community's economic development. The project stressed that the community's residents were the main subjects in the participation. Besides, it emphasized community self-governance and had a good monitoring and guarantee mechanism. The execution of project realized economic development in Bojiwan Village, improvement of villagers' awareness of environmental protection and recovery of ecological environment in Bojiwan wetland.

\subsubsection{Australia's Kakadu National Park Wetland's Participation Mode of "Respecting Community"}

The mode enabled native residents to participate in the park's planning and management closely. The native residents accounted for a majority of members in Park's Management Committee. They possessed the right to engage in any commercial activities and obtained $20 \%$ of the income of park's entrance tickets. The traditional knowledge possessed by native residents was widely applied in formulating the tourism development plan. The mode focused on the functions of community in tourism development, respected the attitude and demands of community, and absorbed the community's reasonable suggestions and advice. Moreover, it closely related tourism development to community development. The community had the dominance and control right of tourism, and benefited from the development of ecological tourism continuously. The execution of the mode got the local community's support, constructed the harmonious relationship with ecological tourism and local community, and realized sustainable development of tourism.

\subsubsection{Yancheng Coastal Wetland Ecological Tourism'S "Community Co-Governance" Participation Mode}

"Community co-governance" refers that ecological tourism destination community and relevant stakeholder group take active part in the maintenance and management of ecological tourism system so that they can maintain the bio-diversity, eco-integrity, ecological service functions and aesthetical values for a long time besides providing satisfactory ecological tourism products and services, realize community's benefits, and promote the sustainable development of the community and tourism industry. The mode stresses the education and training of the community and improves the ability of participation management. It executes the legal guarantee and regulations of "community co-governance", rationally allocates the explicit benefits generated from "community co-governance", provides effective incentives, and provides active external support for "community co-governance". Furthermore, it constructs an effective conflict management mechanism, builds the tourism participation system corresponding to the local community in Yancheng coastal wetland, improves community participation ability, and realizes coordinated development of preservation zone and community. 
1.2.4 Northern Wetland'S “Company + Farmer" Community Participation Mode in Minzhu County, Daowai District, Harbin

The specific action in the mode is that the village committee raised fund to register and establish Shengli Tourism Development Co., Ltd. Farmers could take a wide participation into each position in ecological tourism and wetland sightseeing agriculture. Besides, it carried out systematic and professional training for farmers who could hold shares in the company. Besides, the company bought pension insurances and dividend for farmer and ensured farmers' shareholders' benefits. The execution of the mode helped farmers realize their wish of seeking employment in their hometown, created the wetland tourism sightseeing zone with unique scenery, effectively protected the wetland, and generated sound economic benefits.

The enlightenment on Luoshijiang wetland community's participation mode from the above four practical modes includes: (1) Community participation should emphasize that community's residents are the participation subjects, and respect community's advice and community self-governance. (2) Community participation can introduce external companies to instruct community participation. (3) Community residents' ability construction is necessary to improve their tourism participation ability. (4) There should be corresponding benefit distribution mechanism to ensure that community residents can benefit from the participation process. (5) There should be corresponding guarantee system and effective community conflict management mechanism.

\section{Major Methodologies}

\subsection{Literature Analysis Methodology}

The study widely collects domestic and foreign experts' researches on community participation, community development, ecological tourism, community tourism, residents' perception and behaviors, tourism's effects and so on, summarize and conclude the literatures, and make a summary on previous research results.

\subsection{Field Investigation Methodology}

The research team made various investigations and survey into Luoshijiang wetland's resources, environment, development of ecological tourism and community for many times in 2013. Through a large number of field investigations, the study widely collects information, files and data to lay a foundation for researches.

\subsection{Community Investigation and Interview}

In order to know the social and economic development of Luoshijiang wetland community as well as residents' perception and attitude of wetland environmental protection and development of tourism, the study applies field observation, semi-structured interview, in-depth interviews of key figures, questionnaire survey and other methods, the study gets firsthand information about the population, employment and income of community families, affairs in the preservation zone, participation into tourism matters, perception of ecological tourism, expectations on the development of ecological tourism, etc.

\section{Construction of Community Participation Mode of Luoshijiang Wetland Ecological Tourism}

According to the development of Luoshijiang wetland community, the current situation of management and referential analysis of domestic and foreign community participation, based on the actual situation of Luoshijiang wetland community, the research puts forward three community participation modes, respectively "Erhai Management Bureau + company + village committee, community self-management center + community farmer household mode", "community professional cooperation agency mode" and "farmer self-operation mode". Among them, "Erhai Management Bureau + company + Community self-management center of village committee + community farmer household mode" is the core community participation mode in Luoshijiang wetland community. The other two modes are beneficial supplements of the core mode.

\subsection{Erhai Management Bureau + Company + Community Self-Management Center of Village Committee + Community Farmer Household Mode}

\subsubsection{Erhai Protection \& Management Bureau}

Erhai Protection \& Management Bureau controls the whole wetland's development on behalf of the government. It is responsible for formulating the macro development strategy. Through making a series of macro guiding plans, combining with the actual situation of each village, it steers the development orientation of Luoshijiang wetland community participation.

\subsubsection{Community Self-Management Center of Village Committee}

Community self-management center of village committee is a key part in the organization and management of community participation. It is of great guarantee for the whole community to take part in the construction and 
development of the company's wetland ecological tourism at a high quality. Its major responsibilities include: (1) Handle the internal contradictions of community participation; (2) Exchange information between company and community, management bureau and community, community and community, external market and community; It is responsible for delivering qualified community talents to Luoshijiang Wetland Development Construction Co., Ltd. and other tourism enterprises; (3) Standardize the operation order of community participation and avoid malicious competition; (4) Protect community residents' benefits in taking part in the ecological tourism; (5) Specific organization and implementation of constructing the ability of community participation; (6) Monitor the environmental protection in community tourism participation.

The personnel in community self-management center of village committee are composed of: Village leaders、 Elites and reputable and authoritative personnel in the village and Other volunteers in the village.

\subsubsection{Luoshijiang Wetland Development Construction Co., Ltd.}

The company is one key part in the mode. It undertakes the specific wetland restoration construction, organization and execution of wetland ecological tourism and development of ecological sightseeing agriculture project. Besides, based on its own situation, it should propose the annual elite utilization plan and technical ability requirement plan to community self-management center of village committee.

Main responsibilities and obligations: (1) Propose the annual elite utilization plan and technical ability requirement plan to community self-management center of village committee. (2) Be responsible for providing certain capital for the community ability construction; (3) On the prerequisite of guaranteeing the normal development of the company, expand the working opportunities as many as possible. Accept community residents who are up to the technical requirements to work in the company; (4) Be responsible for paying salary to community personnel who work in the company in full amount; (5) Ensure that Luoshijiang wetland can give its functions into play; (6) Follow all contract signed between farmers;

\subsubsection{Community Farmers}

Community farmers are another key part in the mode. They are the major entities in community participation. They obtain the ability of community participation through the project of community participation ability construction. Moreover, with the ability, they finally make a fortune. The responsibilities and obligations of community farmers include: (1) Protect Luoshijiang wetland that ensure their living; (2) Take an active part in community participation ability construction project according to their own situation; take an active part in Luoshijiang wetland ecological tourism and ecological sightseeing agricultural development; and obtain corresponding income; (3) Abide by all contracts signed with the company (including Labor Contract, Field Leasing Contract, etc.); (4) Actively publicize ecological tourism and ecological sightseeing agriculture of Luoshijiang wetland; (5) Abide by national laws and "village regulations";

\subsubsection{Operating System of the Mode}

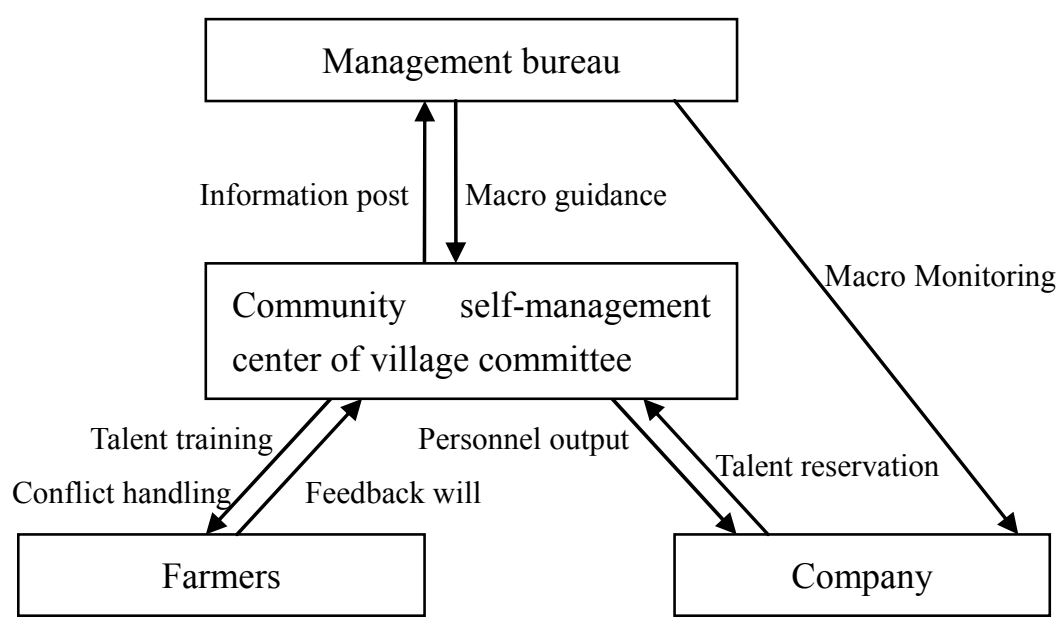

Figure 1. Schematic drawing of operation of "Erhai Management Bureau + company + community self-management center of village committee + community farmer household mode 
Through the community participation mode, it can organize government, company and community residents for unified leading, reasonable planning, unified development and common development so as to realize the common success in Erhai protection, company's development and farmers' wealth.

\subsection{Community Professional Cooperation Agency Mode}

With Rural Professional Cooperation Agency Law coming into effect on July 1st, 2006, guided by the reform of agricultural economic development mode, each field of rural areas is gradually adjusting its structures. Community professional agency mode is also becoming popular. The community professional cooperation agency mode refers to implementing joint development operation based on individual operation for the purpose of seeking for scale economic benefits, realizing resource sharing and advantage supplement. Several or more farmer households cooperate with each other, conduct unified organization and planning, distribute work and collaborate with each other, realize sub-household operation, take common part in the development, reception and service of relaxation agriculture spontaneously or under the organization and coordination of rural collectivity (village committee".

Many farmers in Luoshijiang wetland community are planting orchid and raising cows now. However, the scale is too small. Their technical ability is poor. They sell the products with the unit of household. A joint force is not formed. Under the current situation, the community can carry out orchid planting and cow breeding agency project. The cooperation agency provides technology and sells products to the outside. Moreover, on the basis, relying on the development of wetland ecological tourism, it carries out community planting and breeding sightseeing agriculture project.

\subsection{Farmer Household's Self-Operation Mode}

Farmer household's self-operation mode refers to restoring and constructing their own agricultural field, breeding field and forestry, orchard and house so as to complete the commercial development mode of rural tourism reception service. The mode is frequently seen. In particular, "Relaxation in Rural Area" mode is the most outstanding. The farmer households with superior foundation in Luoshijiang wetland community can make use of their own residential houses and yards to provide local food, chess \& card entertainment, balls \& fitness, accommodation and other services for tourists. In this way, they can not only relieve the catering and reception pressure on Luoshijiang wetland, but also help farmer households seek wealth.

\section{Research on the System of Guaranteeing Community Participation in Luoshijiang Wetland Ecological Tourism}

In order to ensure that community participation mode in Luoshijiang ecological tourism can be effectively and positively executed, a feasible and effective guarantee mechanism is in need.

\subsection{Establish Regulations on Community Participation}

Each benefit entity tends to seek for personal interests. On the prerequisite of protecting the wetland, in order to enable the community to better take part in the wetland ecological tourism and wetland ecological sightseeing agriculture, the community should construct a legal system that supports the development of Luoshijiang wetland community based on Wetland Convention, Environmental Protection Law of the People's Republic of China, Planning of Execution of National Wetland Protection Project (2005-2010), Regulations on Management of Erhai, Bai Ethnical Autonomous Religion in Dali, Yunnan Province and other rules to clarify the rights, responsibilities and obligations in the construction of Luoshijiang wetland. The regulations and systems that should be constructed include: (1) regulations on community participation from the governmental perspective; (2) regulations on community participation at the company's level; (3) regulations on community participation at the community level.

\subsection{Facilitate Legal Construction}

In the process of community participation, the legal construction in Luoshijiang wetland community should be stressed. First of all, the contract construction can be launched. The farmers in the community should abide by the contracts and agreement. The establishment of contracts demonstrates the legal construction of community participation in the tourism development. In the process of Luoshijiang wetland community participation, it is unavoidable that disputes, contradictions and even conflicts will occur. Therefore, contracts can ensure fair and equitable handling. Second, the habitual standard formed in the community is an effective supplement of contract participation. Through "regulations in the village and among residents", they can carry out self-management and self-maintenance. By adopting legal construction in the community, the community residents' benefits and behaviors can be ensured and standardized. It is also the foundation to ensure the coordinated participation of Luoshijiang wetland community. 


\subsection{Set Up the System of Risk Fund}

Community participation into Luoshijiang wetland ecological tourism will encounter certain risks in the future. On the one hand, they come from the natural risks in the development of the wetland. On the other hand, they come from external risks outside the tourism market. In order to control the risks at the minimum level, some compensation must be made for the risk losses. Risk fund system must be established. The risk fund for Luoshijiang wetland community tourism development can be established in multiple methods: First, establish the shared held by Luoshijiang wetland community residents according to a certain percentage. Before allocation every year, a small part is deducted from the dividend provided by Luoshijiang Wetland Development Construction Co., Ltd. and common operation profits as the risk fund. Then, the amount of risk fund can be enriched year by year. Second, co-establishment by the government and self-operating enterprises for community tourism: The government allocates certain amount from the financial reserve and community self-operating tourism enterprises allocate a part from their profits as risk fund every year. Third, Luoshijiang Wetland Development Construction Co., Ltd., government, community self-operating tourism enterprises establish and use the fund according to their proportional shareholding.

\section{References}

Peter, E. M. (1985). Tourism: A community Approach. New York and London: Thomson Learning, 12-34. Retrieved from http://www.sciencedirect.com/science/article/pii/0261517786900129

Wesche, R., \& Drumm, A. (1999). Defending the Rainforest, Action Amazonia. Quito, Ecuador, 148-156.

Weng, J., \& Yang, K. Z. (2004). A study on landscape company + peasant model: A case of Chongdug resort area. Economic Survey, 1, 135-138.

Wu, Z. J., \& Ye, Y. (2005). The discussion about ethnical community tourism benefit distribution and validity of residents' participation - Take Guilin Longsheng Longji terrace scenic spot Pingan village as example. Journal of Guangxi Economic Management Cader College, 3, 51-55. Retrieved from http://www.cqvip.com/ QK/81642X/2005003/20055036.html

Bao, J. G., \& Sun, J. X. (2006). A contrastive study on the difference in community participation in tourism between China and the west, ACTA Geographica Sinica, 4, 401-403. Retrieved from http://www.cqvip.com/ QK/90059X/200604/21702820.html

\section{Copyrights}

Copyright for this article is retained by the author(s), with first publication rights granted to the journal.

This is an open-access article distributed under the terms and conditions of the Creative Commons Attribution license (http://creativecommons.org/licenses/by/3.0/). 